\title{
Mosquito fauna on the Cape Verde Islands (West Africa): an update on species distribution and a new finding
}

\author{
Joana Alves ${ }^{1,2}$, Bruno Gomes ${ }^{1}$, Regina Rodrigues ${ }^{2}$, João Silva ${ }^{1,5}$, Ana Paula Arez ${ }^{1,5}$, João Pinto ${ }^{1,3}$, \\ and Carla Alexandra Sousa ${ }^{3,4 凶}$
}

${ }^{1}$ Centro de Malária e outras Doenças Tropicais, Instituto de Higiene e Medicina Tropical, Universidade Nova de Lisboa. Rua da Junqueira 100, 1349-008 Lisboa, Portugal

${ }^{2}$ Direcção Geral de Saúde, Ministério da Saúde de Cabo Verde. Largo Desastre da Assistência, Chã d'Areia, Santiago - Praia, C.P. 719, Cabo Verde

${ }^{3}$ Unidade de Entomologia Médica, Instituto de Higiene e Medicina Tropical, Universidade Nova de Lisboa. Rua da Junqueira 100, 1349-008 Lisboa, Portugal

${ }^{4}$ Unidade de Parasitologia e Microbiologia Médicas, Instituto de Higiene e Medicina Tropical, Universidade Nova de Lisboa. Rua da Junqueira 100, 1349-008 Lisboa, Portugal

${ }^{5}$ Unidade de Malária, Instituto de Higiene e Medicina Tropical, Universidade Nova de Lisboa. Rua da Junqueira 100, 1349008 Lisboa, Portugal

Received 16 February 2010; Accepted 6 June 2010

\begin{abstract}
To evaluate the risk of transmission of vector-borne diseases, regular updates of the geographic distribution of insect vectors are required. In the archipelago of Cape Verde, nine mosquito species have been reported. Of these, four are major vectors of diseases that have been present in the archipelago: yellow fever, lymphatic filariasis, malaria and, currently, an outbreak of dengue. In order to assess variation in mosquito biodiversity, we have carried out an update on the distribution of the mosquito species in Cape Verde, based on an enquiry of 26 unpublished technical reports (1983-2006) and on the results of an entomological survey carried out in 2007. Overall, there seems to be a general trend for an expansion of biological diversity in the islands. Mosquito species richness was negatively correlated with the distance of the islands from the mainland but not with the size of the islands. Human- and/or sporadic climatic-mediated events of dispersal may have contributed to a homogenization of species richness regardless of island size but other ecological factors may also have affected the mosquito biogeography in the archipelago. An additional species, Culex perexiguus, was collected for the first time in the archipelago during the 2007 survey. Journal of Vector Ecology 35 (2): 307-312. 2010.
\end{abstract}

Keyword Index: Culicidae, Cape Verde Islands, vector-borne diseases, Culex perexiguus.

\section{INTRODUCTION}

To evaluate the risk of transmission of vector-borne diseases in a given region, a continuous updating of the geographic distribution of insect vectors is required (Weaver and Reisen 2010). This knowledge has long been a priority for the health authorities of the archipelago of Cape Verde. This archipelago is located approximately $500 \mathrm{~km}$ off the coast of Senegal, West Africa, and is composed of nine inhabited islands clustered in two groups: St. Antão, S. Vicente, S. Nicolau, Sal, and Boa Vista form the Barlavento group; Maio, Santiago, Fogo, and Brava constitute the Sotavento group. Medical entomology surveys were initiated in the 1920s after the discovery of Anopheles gambiae s.l. (then named Anopheles costalis) by A. Vieira on Santiago Island (Sant'Anna 1920). Since then, a total of nine mosquito species have been annotated for the islands (reviewed in Ribeiro et al. 1980) and their findings published mainly in Portuguese written publications of limited diffusion. Of the nine recorded species, four are major vectors of human diseases.

Anopheles (Celia) arabiensis Paton, 1905, is the only member of the Anopheles gambiae complex present in Cape Verde (Cambournac et al. 1982). It is a major malaria vector in sub-Saharan Africa and it has been incriminated as the vector of several malaria outbreaks recorded in the archipelago over the last decades (Alves et al. 2006). It was also the vector of lymphatic filariasis in Santiago Island (Franco and Menezes 1955) as it happens in the west of sub-Saharan Africa (Wright 1974). Aedes (Stegomya) aegypti Linnaeus, 1762, is the most competent yellow fever and dengue vector and it was reported for the first time by Sant'Anna in 1931 (cited by Ribeiro et al. 1980) on S. Vicente Island. Finally, two species of the Culex pipiens complex, both with significant medical importance, have been recorded for the archipelago. Culex (Culex) quinquefasciatus Say, 1823, the well-known vector of lymphatic filariasis, was first reported by Meira et al. (1947) in S. Nicolau. The nominal species of the complex, Culex (Culex) pipiens Linnaeus, 1758, implicated in the transmission of arbovirus such as the West Nile virus, was reported for the first time by Ribeiro et al. (1980) in four islands of the archipelago. Based on the morphology of male genitalia, the authors have also referenced the presence of hybrids between $C x$. 
pipiens and Culex quinquefasciatus.

The Cape Verde archipelago is classified as having a Sahelian arid climate. However, each island has specific topographies and displays differences in terms of microclimate and vegetation cover. Environmental and social changes, as well as increased travelling within the archipelago and between the islands and other countries, may result in changes in the patterns of mosquito distribution and abundance. To address this possibility, we have carried out an update on the distribution of the mosquito species in Cape Verde, based on an inquiry of unpublished technical reports and on the results of an entomological survey carried out on the four Sotavento islands of the archipelago.

\section{MATERIALS AND METHODS}

\section{Bibliographic research}

Unpublished data on mosquito species distribution in the archipelago of Cape Verde was compiled from technical reports of the Ministry of Health of Cape Verde. These refer to entomological surveys based on larval collections performed in routine surveillance operations carried out between 1983 and 2006, in seven of the nine inhabited islands (excluding St. Antão and Brava). From each report, data on the presence/absence of mosquito species was collected for each island and compared to previously published records. These records, together with the results of a countrywide mosquito survey, have been assembled in a book by Ribeiro et al. (1980) that served as a reference in this study for the mosquito fauna in Cape Verde until 1980. In addition, two publications concerning new species findings after 1980 for the islands were also consulted (Cambournac et al. 1982, 1984).

\section{Mosquito collections and morphological identification}

Entomological surveys were carried out during the months of November and December 2007 on the four islands of the Sotavento group of the archipelago of Cape Verde: Maio, Santiago, Fogo, and Brava (Figure 1). Immature culicids were collected using standard sampling methods with dippers and pipettes. A variety of potential breeding sites such as ponds, pools, swamps, pits, tanks, wash basins, septic tanks, and other aquatic habitats were inspected and geo-referenced with a portable GPS. All immature mosquitoes collected were transported to a laboratory in Praia (Santiago Island), where larvae were reared until the emergence of adults. After emergence, mosquitoes were killed by freezing and morphologically identified to species/complex using the identification keys of Ribeiro and Ramos (1995). Specimens of An. gambiae and $C x$. pipiens complexes were individually preserved in tubes filled with silica gel and kept at room temperature until DNA extraction.

\section{Molecular identification of mosquitoes}

Genomic DNA was extracted from individual females previously identified as $C x$. pipiens s.l. and An. gambiae s.l. using the method described by Collins et al. (1988).
Polymerase Chain Reaction (PCR) assays were performed according to the protocols of Scott et al. (1993) and Smith and Fonseca (2004) to identify the members of the $A n$. gambiae and Cx. pipiens complexes, respectively. Amplified products were separated by $2 \%$ agarose gel electrophoresis and species-specific fragment sizes were visualized and photographed under UV light.

\section{Data analysis}

Species richness (i.e., number of different species in a given area) for each island was calculated based on the records derived from historical reports and contemporary collections. Correlation analysis was performed to test for associations between species richness per island and distance to mainland or island size. Calculations were done using SPSS ${ }^{\bullet}$ statistical software (SPSS Inc.).

\section{RESULTS}

Twenty-six unpublished reports referring to field entomological surveys carried out in seven islands between 1983 and 2006 were consulted. Data on mosquito species' presence/absence was compiled along with those species annotated before 1980. These results are summarized in Figure 1. A total of six species and two species complexes were reported for the archipelago until 2006. No information on species complexes composition was present in unpublished reports. Overall, there appeared to be a general trend for an expansion of biological diversity in the islands. Two new species were annotated since 1980 (Cx. ethiopicus and $C x$. tigripes) and the distribution of each species seems to be spreading throughout the islands of the archipelago, with eight new annotations in five different islands since 1980. The only exception appears to be Ae. aegypti whose distribution seems to be contracting in the Barlavento group, although no control measures have been recently implemented against this vector. Anopheles pretoriensis and $C x$. pipiens s.l. are the most stable taxa, presenting the same distribution patterns since 1980, with the latter being the only one reported in all the islands of the archipelago. Santiago was the only island where all taxa reported for the archipelago were found, whereas S. Vicente was the island with lower species richness.

There was a significant negative correlation between species richness per island and distance of the islands to the mainland (Spearman's rank correlation coefficient: $\rho=$ -0.771, $P=0.015,2$-tailed test). However, no correlation was found between species richness and island size (Spearman's rank correlation coefficient: $\rho=0.337, P=0.375,2$-tailed test).

A total of 173 water collections was sampled during the 2007 survey. Of these, 136 (78.6\%) were located on Santiago Island, in 27 localities of the nine districts. On the other islands, the number of potential breeding sites sampled was $12(6.9 \%)$ in two of the three districts of Fogo Island, seven (4.1\%) in Brava, and 18 (10.4\%) in Maio. Seventy-nine (45.7\%) water collections were positive for mosquito larvae. There were $61(44.9 \%)$ positive breeding sites on Santiago, 


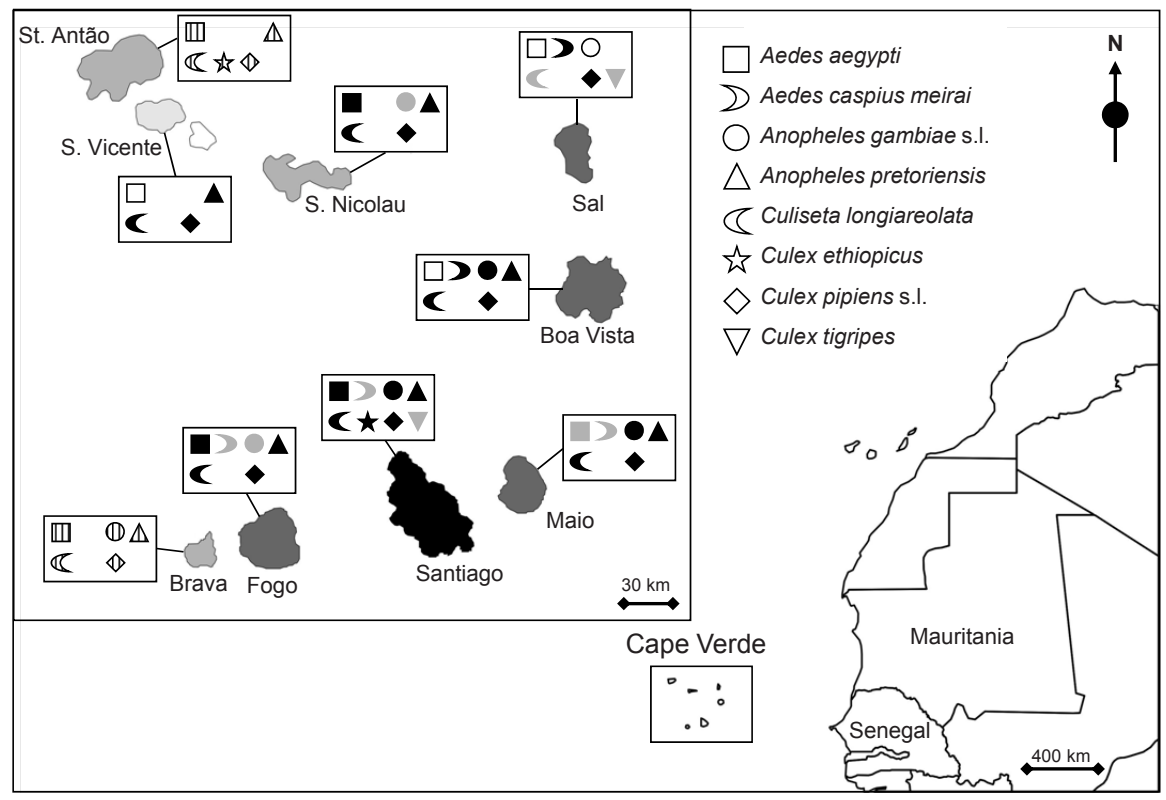

Figure 1. Choropleth map of Cape Verde, showing mosquito species richness and composition according to bibliographic records. Shading intensity of the islands reflects species richness. Each species is represented by a symbol, according to the label on the map. Black symbols: species annotated before 1980 (Ribeiro et al. 1980) and also recorded in unpublished reports from 1983-2006; White symbols: species annotated before 1980 (Ribeiro et al. 1980) but absent in unpublished reports from 1983-2006. Gray symbols: species annotated only in unpublished reports from 1983-2006. Striped symbols: These records derive only from Ribeiro et al. (1980) as no documented mosquito surveys were performed in these islands in 1983-2006.

Table 1. Mosquito species/complex distribution based on the entomological survey of 2007.

\begin{tabular}{lcccccccc}
\hline \multirow{2}{*}{ Island } & \multicolumn{2}{c}{ Maio } & \multicolumn{2}{c}{ Santiago } & \multicolumn{2}{c}{ Fogo } & \multicolumn{2}{c}{ Brava } \\
Species & $\mathrm{N}$ & $\%$ & $\mathrm{~N}$ & $\%$ & $\mathrm{~N}$ & $\%$ & $\mathrm{~N}$ & $\%$ \\
\hline Aedes aegypti & 0 & 0.0 & 218 & 40.2 & 2 & 1.5 & 8 & 8.6 \\
Aedes caspius & 11 & 3.6 & 0 & 0.0 & 0 & 0.0 & 0 & 0.0 \\
Anopheles gambiae & $\mathbf{0}$ & $\mathbf{0 . 0}$ & $\mathbf{1 0 0}$ & $\mathbf{1 8 . 5}$ & $\mathbf{0}$ & $\mathbf{0 . 0}$ & $\mathbf{0}$ & $\mathbf{0 . 0}$ \\
$\quad$ Anopheles arabiensis & 0 & 0.0 & 98 & 100.0 & 0 & 0.0 & 0 & 0.0 \\
Anopheles pretoriensis & 1 & 0.3 & 43 & 7.9 & 12 & 9.2 & 4 & 4.3 \\
Culex ethiopicus & 0 & 0.0 & 26 & 4.8 & 0 & 0.0 & 0 & 0.0 \\
Culex univittatus & $\mathbf{0}$ & $\mathbf{0 . 0}$ & $\mathbf{1 3}$ & $\mathbf{2 . 4}$ & $\mathbf{0}$ & $\mathbf{0 . 0}$ & $\mathbf{0}$ & $\mathbf{0 . 0}$ \\
$\quad$ Culex perexiguus & 0 & 0.0 & 13 & 100.0 & 0 & 0.0 & 0 & 0.0 \\
Culex pipiens & $\mathbf{2 9 8}$ & $\mathbf{9 6 . 1}$ & $\mathbf{1 3 5}$ & $\mathbf{2 5 . 0}$ & $\mathbf{1 0 3}$ & $\mathbf{7 9 . 2}$ & $\mathbf{6 2}$ & $\mathbf{6 6 . 7}$ \\
$\quad$ Culex pipiens s.s. & 13 & 20.6 & 0 & 0.0 & 0 & 0.0 & 0 & 0.0 \\
$\quad$ Culex quinquefasciatus & 8 & 12.7 & 55 & 100.0 & 22 & 61.1 & 31 & 100.0 \\
$\quad$ Hybrids & 42 & 66.7 & 0 & 0.0 & 14 & 38.9 & 0 & 0.0 \\
Culex tigripes & 0 & 0.0 & 7 & 1.3 & 7 & 5.4 & 0 & 0.0 \\
Culiseta longiareolata & 0 & 0.0 & 0 & 0.0 & 6 & 4.6 & 19 & 20.4 \\
\hline Total & & 310 & & 542 & & 130 & 93 \\
\hline
\end{tabular}

$N$ : number of specimens; \%: Percentage of mosquito species per island. Sibling species complexes are highlighted in bold. The rows below each complex indicate the relative proportions (in percentage) of each sibling species (and hybrids) identified on each island by PCR (in the case of the An. gambiae complex, $N=98$, and of the $C x$. pipiens complex, $N=185$ ) or by morphological characters (in the case of $C x$. univittatus complex, $N=13$ ). 
nine $(75.0 \%)$ on Fogo, six $(85.7 \%)$ on Brava, and three on Maio (16.7\%).

From 1,104 emerged adults, it was possible to morphologically identify 1,075 (97.4\%) specimens (Table 1). All taxa previously annotated for the archipelago were collected during this survey. Culex pipiens s.l. was the most abundant mosquito, being found on the four islands. Molecular analysis of a subsample of 185 specimens revealed the presence of two species of the complex, namely $C x$. quinquefasciatus and $C x$. pipiens s.s., as well as individuals with a hybrid PCR band pattern between the two species. Culex quinquefasciatus was collected on all islands, being the only member of the complex in Brava and Santiago islands. Culex pipiens s.s. was found only on Maio. Hybrids were detected on Maio and Fogo. Anopheles gambiae s.l. was found only on Santiago. Anopheles arabiensis was the only species of the complex identified in the subsample of 98 specimens.

In addition to the species already annotated for the archipelago, the presence of a member of the Culex univittatus complex is here annotated for the first time in Cape Verde. The specimens were collected in two localities of Santiago Island: Cidade Velha $\left(14^{\circ} 55^{\prime} \mathrm{N} / 23^{\circ} 37^{\prime} \mathrm{W}\right)$, Ribeira Grande District (five females and five males); João Garrido $\left(15^{\circ} 01^{\prime} \mathrm{N} / 23^{\circ} 34^{\prime} \mathrm{W}\right)$ São Domingos District (one female and two males). Based on the morphology of males and females, these mosquitoes were identified as Culex perexiguus Theobald, 1903. The males presented genitalia with broad $g$ seta and short ventral arms of the lateral plate that excluded the possibility of misidentification with Cx. univittatus s.s. Theobald, 1901 (Jupp 1970, White 1975, Harbach 1988, Jupp and Harbach 1990). All females exhibited a fine line of white scales at the base of costa, the most reliable character to distinguish $C x$. perexiguus (with pale scales) from $C x$. neavei Theobald, 1906 (without pale scales) (Jupp and Harbach 1990). Other morphological characteristics observed that are attributable to $C x$. perexiguus were the presence in the hind tibias of distinct anterior and posterior pale stripes and very well marked apical spots; postspiracular areas usually more than half covered with white scales; fore femurs with anterior, but sometimes inconspicuous, pale stripes; veins 2A with only two to ten sparsely distributed scales and male genitalia presenting $\mathrm{f}$ seta with swollen tips.

\section{DISCUSSION}

On volcanic islands such as Cape Verde, biological diversity of insect species tends to be higher on the larger islands and closer to the mainland (Gillespie and Roderick 2002). This trend is only partially found in Cape Verde. A significant negative correlation was detected between species richness and distance of the islands to the mainland, in accordance with expectations of island biogeography theory. However, with the exception of Santiago, the larger island that did display the highest diversity, all remaining islands presented similar numbers of species in spite of their differing sizes $\left(64 \mathrm{~km}^{2}-779 \mathrm{~km}^{2}\right)$. A possible explanation is that human-mediated and/or sporadic climatic-mediated events of inter-islands mosquito dispersal could have promoted a homogenization of mosquito diversity in the archipelago (Lounibos 2002). However, our results need to be addressed with caution. Due to limitations in the bibliographic records, it was impossible to standardize information on species abundance. This precluded estimation of species diversity (i.e., number of species weighted by an abundance measure) which is a much more robust indicator of biodiversity. In addition, many other ecological factors are likely to affect species richness in the islands. These include differences between islands in climate, vegetation, host presence, urbanization (e.g., the capital and main city of the country is in Santiago) and differences in human movements between the islands and mainland (e.g., tourism is more developed in certain islands such as Boa Vista and Sal). More detailed bio-ecological studies, preferably complemented with population genetic data, are thus required in order to ascertain the biogeography of mosquito populations in the archipelago.

The four major mosquito vectors with the greatest medical importance are found in Cape Verde. The primary malaria vector, $A n$. arabiensis, is the only member of the An. gambiae complex so far described for the islands (Cambournac et al. 1982, Pinto et al. 1999). In this study, An. arabiensis was found only on Santiago, which is the only island where occasional malaria outbreaks still occur (Alves et al. 2006). However, this species was also identified on Fogo and Boavista (Cambournac et al. 1982) and previous records for the complex include S. Nicolau, Sal, Brava, and Maio, albeit without species determination. The exclusive presence of An. arabiensis in Cape Verde is consistent with the Sahelian conditions of the archipelago, as this member of the An. gambiae complex is most tolerant to aridity (Coetzee et al. 2000, Coluzzi et al. 2002).

The $C x$. pipiens complex is represented in Cape Verde by $C x$. quinquefasciatus and $C x$. pipiens, the most ubiquitous mosquitoes in the tropical and temperate regions of the globe, respectively. Furthermore, molecular identification indicated considerable numbers of putative hybrids on two of the islands (Maio and Fogo), confirming previous reports based on the morphology of male genitalia (Ribeiro et al. 1980). The subtropical location of the archipelago is likely to present adequate environmental conditions for a contact zone between the two species. A similar situation is found in the U.S.A., where a hybrid zone between $C x$. pipiens s.s. and $C x$. quinquefasciatus is well-documented (Kothera et al. 2009). On mainland Africa, there is no known hybrid zone between the two sibling species, which probably reflects the effect of the Sahara desert as a geographic barrier to their distribution.

Aedes aegypti displayed considerable variation in distribution over time. Before 1980 it was reported on all islands except Maio. Subsequent unpublished reports (1983-2006) annotated Ae. aegypti for Maio but also pointed to its absence from three Barlavento islands. In the present survey, Ae. aegypti was collected on only three of the four islands (again absent in Maio), but was the most abundant mosquito on Santiago Island. This vector was 
probably involved in the recent dengue fever epidemic that has affected the Sotavento Islands of the archipelago (Brava, Fogo, Santiago, and Maio) since October 2009 (WHO 2009). The absence of Ae. aegypti from our survey on Maio may reflect an insufficient sampling effort, although it is not clear from the literature if the dengue cases on this island were a result of autochthonous transmission. Therefore, additional mosquito surveys using more diverse sampling methods and virological analyses are required to directly incriminate this species as the vector of dengue in Cape Verde and to further detail the species distribution in the islands.

This study describes, for the first time in Cape Verde, the presence of Culex perexiguus, a member of the $C x$. univittatus complex. This complex includes three species: Culex univittatus, Culex neavei, and Culex perexiguus. The status of full species for the three members was confirmed by crossing experiments (Jupp 1971, Jupp and Harbach 1990). The species also present differences regarding vector competence (Jupp et al. 1986), mating behavior (Gad et al. 1987) and can be morphologically identified by a set of minor features of the adults (Jupp 1971, 1972, Harbach 1988, Jupp and Harbach 1990). Culex perexiguus is found in arid regions of northern and eastern Africa and from southwestern Asia to India (Jupp and Harbach 1990). It is a competent vector of West Nile, Sindbis, and Rift Valley fever viruses (Jupp et al. 1986, Turell et al. 1996).

Of the ten mosquito species so far reported for Cape Verde, half (An. gambiae, Ae. aegypti, Cx. quinquefasciatus, $C x$. pipiens s.s., and $C x$. perexiguus) are considered major vectors of parasites (e.g., plasmodia and filaria) and viruses (e.g., dengue, West Nile). The physical isolation from mainland Africa coupled with an arid climate most likely have prevented the endemic establishment of vectortransmitted diseases in the archipelago, such as malaria or dengue. However, whenever environmental conditions more suitable for increased mosquito breeding/survival are coincident with the presence of a pathogen reservoir in Cape Verde, the risk for epidemics increases dramatically. Vector monitoring strategies should therefore be re-evaluated and the creation of a national program for mosquito surveillance and control based on the concepts and practices of WHO early warning systems should be considered (WHO 2004).

\section{Acknowledgments}

We are grateful to the population of Cape Verde for collaborating in this study. We thank the General Department of Health (J. Pereira), the delegates and technicians of Health Care Units of St. Cruz, Tarrafal, and St. Catarina (A. Veiga and E. Semedo, Sr. João, Sr. Mário, and Sr. Belmiro), and J. Pina, Sr. Luís, and F. Robalo of the National Malaria Program, for logistic support in the field. We thank T. Novo (IHMT, Portugal), J.L. Vicente, and T. Silva (CMDT/IHMT, Portugal) for assistance with the lab work. We also thank three anonymous reviewers for the input given in a previous version of the article. This study was supported by Fundação para a Ciência e a Tecnologia/ FEDER, Portugal (POCI/BIA-BDE57650/2004, PPCDT/
SAU-ESP/55110/2004), Financiamento Programático do Laboratório Associado CMDT.LA/IHMT and WHO/Cabo Verde. J.A. and B.G. are Ph.D. fellows of the Fundação para a Ciência e a Tecnologia/FEDER, Portugal (SFRH/ BD/153451/2005 and SFRH/BD/36410/2007).

\section{REFERENCES CITED}

Alves, 1, A.L. Roque, P. Cravo, T. Valde, T. Eelinek, V.E. Rosário and A.P. Arez 2006. Epidemiological characterization of Plasmodium falciparum in the Republic of Cabo Verde: implications for potential large-scale re-emergence of malaria. Malar. J. 5: 32.

Cambournac, F.J.C., M.C. Oliveira, A. Correia, M.A. Coutinho, J. Tourinho, and B. Soares. 1984. Culex (Lutzia) tigripes (Grandpré); Mais uma espécie nova para Cabo Verde. An. do Inst. de Hig. e Med. Trop. 10: 41-46.

Cambournac, F.J.C., V. Petrarca, and M. Coluzzi. 1982. Anopheles arabiensis in the Cape Verde Archipelago. Parassitologia 24: 265-267.

Coetzee, M., M. Craig, and D. le Sueur. 2000. Distribution of African malaria mosquitoes belonging to the Anopheles gambiae complex. Parasitol. Today 16: 74-77.

Collins, F.H., V. Finnerty, and V. Petrarca. 1988. Ribosomal DNA-probes differentiates five cryptic species in the Anopheles gambiae complex. Parassitologia 30: 231240.

Coluzzi, M., A. Sabatini, A. della Torre, M.A. Di Deco, and V. Petrarca. 2002. A polytene chromosome analysis of the Anopheles gambiae species complex. Science 298: 1415-1418.

Franco, A. and A. Menezes. 1955. A filaríase autóctone ( $W$. bancrofti) na ilha de Santiago (Estudo preliminar). Ann. Inst. Med. Trop. 12: 369-393.

Gad, A.M., S. El Said, A.N. Hassan, and A. Shoukry. 1987. The distribution and ecology of the mosquitoes in the Red Sea Governorate, Egypt. J. Egypt. Soc. Parasitol. 17: 207-221.

Gillespie, R.G. and G.B. Roderick. 2002. Arthropods on islands: Colonization, speciation and conservation. Annu. Rev. Entomol. 47: 595-632.

Harbach, R.E. 1988. The mosquitoes of the subgenus Culex in southwestern Asia and Egypt (Diptera: Culicidae). Contrib. Am. Entomol. Inst. 24: 52-61.

Jupp, P.G. and R.E. Harbach. 1990. Crossmating and morphological studies of Culex neavei and Culex perexiguus (Diptera: Culicidae) to elucidate their taxonomic status. Mosq. Syst. 22: 1-10.

uupp, P.G, B.M. McIntosh, and N.K. Blackburn. 1986. Experimental assessment of the vector competence of Culex (Culex) neavei Theobald with West Nile and Sindbis viruses in South Africa. Trans. R. Soc. Trop. Med. Hyg. 80: 226-230.

Jupp, P.G. 1970. The taxonomic status of Culex (Culex) univittatus Theobald (Diptera: Culicidae) in South Africa. Mosq. Syst. 2: 9-16.

Jupp, P.G. 1971. The taxonomic status of Culex (Culex) 
univittatus Theobald (Diptera: Culicidae) in South Africa. J. Entomol. Soc. South Af. 34: 339-357.

Jupp, P.G. 1972. A morphological study of Culex (Culex) univittatus Theobald and Culex (Culex) neavei Theobald from various African countries. Mosq. Syst. 4: 103-113.

Kothera, L., E.M. Zimmerman, C.M. Richards, and H.M. Savage. 2009. Microsatellite characterization of subspecies and their hybrids in Culex pipiens complex (Diptera: Culicidae) mosquitoes along a north-south transect in the central United States. J. Med. Entomol. 46: 236-248.

Lounibos, L.P. 2002. Invasions by insect vectors of human disease. Annu. Rev. Entomol. 47: 233-266.

Meira, M.T.V, J.F.P Nogueira, and T.S. Simões. 1947. Observações sobre o sezonismo nas ilhas do Sal, Boa Vista e S. Nicolau (Cabo Verde). Ann. Inst. Med. Trop. 4: 213-238.

Pinto, J., C.A. Sousa, A.P. Arez, J. Alves, D. Mondiano, V. Petrarca, J.D. Charlwood, and V. do Rosário. 1999. Assessment of malaria transmission in an area with very low mosquito density. Res. Rev. Parasitol. 59: 2326.

Ribeiro, H. and H.C. Ramos. 1995. Guia ilustrado para a identificação dos mosquitos de Angola. Bol. Soc. Portuguesa Entomol. Suppl. 4. 287 pp.

Ribeiro, H., H.C. Ramos, R.A. Capela, and C.A. Pires. 1980. Os mosquitos de Cabo Verde (Diptera: Culicidae) - sistemática, distribuição, bioecologia e importância médica. Junta de Investigações Científicas do Ultramar, Lisboa. 141 pp.
Sant'Anna, J.F. 1920. Anofelíneos de Portugal e das Colónias. Ensaios de entomologia médica com aplicação ao estudo do problema do sezonismo, Lisboa.

Scott, J.A., W.G. Brogdon, and F.H. Collins. 1993. Identification of single specimens of the Anopheles gambiae complex by the polymerase chain reaction. Am. J. Trop. Med. Hyg. 49: 520-529.

Smith, J.L. and D.M. Fonseca. 2004. Rapid assays for identification of members of the Culex (Culex) pipiens complex, their hybrids, and other sibling species (Diptera: Culicidae). Am. J. Trop. Med. Hyg. 70: 339345.

Turell, M.J., S.M. Presley, A.M. Gad, S.E. Cope, D.J. Dohm, J.C. Morrill, and R.R. Arthur. 1996. Vector competence of Egyptian mosquitoes for Rift Valley fever virus. Am. J. Trop. Med. Hyg. 54: 136-139.

Weaver, S.C. and W.K. Reisen. 2010. Present and future arboviral threats. Antiviral Res. 85: 328-345.

White, G.B. 1975. Notes on a catalogue of Culicidae of the Ethiopian region. Mosq. Syst. 7: 303-344.

W.H.O. 2004. Malaria epidemics: forescasting, prevention, early detection and control. From policy to practice. Available from World Health Organization, Geneve. http://www.who.int/malaria/docs/Leysinreport.pdf.

W.H.O. 2009 Dengue fever, Cape Verde. Wkly Epidemiol. Rec. 84: 469.

Wright, G.B. 1974. The Anopheles gambiae complex and disease transmission in Africa. Trans. R. Soc. Trop. Med. Hyg. 68: 278-301. 